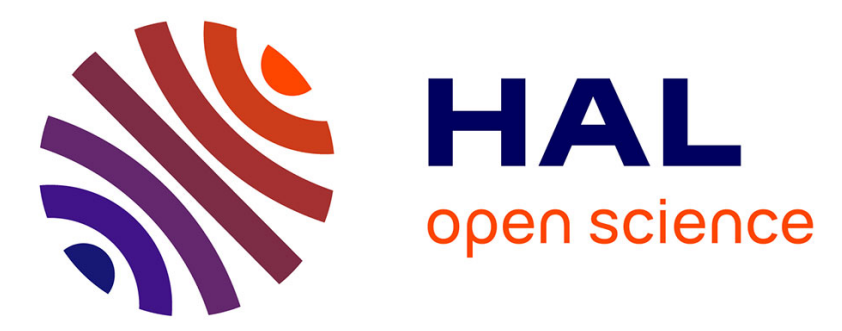

\title{
Copula-based local dependence among energy, agriculture and metal commodities markets
}

\author{
Claudiu Tiberiu Albulescu, Aviral Kumar Tiwari, Qiang Ji
}

\section{To cite this version:}

Claudiu Tiberiu Albulescu, Aviral Kumar Tiwari, Qiang Ji. Copula-based local dependence among energy, agriculture and metal commodities markets. 2020. hal-02501815v2

\section{HAL Id: hal-02501815 \\ https://hal.science/hal-02501815v2}

Preprint submitted on 1 Apr 2020

HAL is a multi-disciplinary open access archive for the deposit and dissemination of scientific research documents, whether they are published or not. The documents may come from teaching and research institutions in France or abroad, or from public or private research centers.
L'archive ouverte pluridisciplinaire HAL, est destinée au dépôt et à la diffusion de documents scientifiques de niveau recherche, publiés ou non, émanant des établissements d'enseignement et de recherche français ou étrangers, des laboratoires publics ou privés. 


\title{
Copula-based local dependence among energy, agriculture and metal
}

\section{commodities markets}

\author{
Claudiu T. Albulescu ${ }^{\mathrm{a} *}$, Aviral K. Tiwari ${ }^{\mathrm{b}}$, Qiang Ji ${ }^{\mathrm{c}, \mathrm{d}}$ \\ ${ }^{a}$ Management Department, Politehnica University of Timisoara, Timisoara, Romania \\ ${ }^{\mathrm{b}}$ Rajagiri Business School, Rajagiri Valley Campus, Kochi, India \\ ${ }^{\mathrm{c}}$ Institutes of Science and Development, Chinese Academy of Sciences \\ ${ }^{\mathrm{d}}$ School of Public Policy and Management, University of Chinese Academy of Sciences, Beijing, China
}

\begin{abstract}
This paper studies the extreme dependencies among energy, agriculture and metal commodities markets, with an emphasis on local co-movements. By applying a novel, copulabased, local Kendall's tau approach to measure nonlinear local dependence in regions, we identified asymmetric co-movements in and between bull and bear markets, as well as the changing trend in the degree of co-movements. Starting from a non-parametric mixture copula, we found that commodities markets' co-movements increase in extreme situations. In addition, we found a stronger dependence between energy and other commodities markets at lower tails. Therefore, we showed that the energy market can offer diversification solutions for risk management in the case of extreme bull market events.
\end{abstract}

Keywords: energy prices; commodities markets; local dependence; co-movements; mixture copula; local Kendall's tau

JEL Classification: C22; G11; G15; Q40

\footnotetext{
*Corresponding author. E-mail address: claudiu.albulescu@upt.ro, claudiual@yahoo.com.
} 


\section{Introduction}

Energy prices' co-movements with other commodities' prices have generated a huge body of literature, given their implications for the economy. We have added to this literature by studying the extreme co-movements among energy, agriculture and metal commodities markets ${ }^{1}$ using sub-indices from the Rogers International Commodity Index. Unlike previous studies, we focussed on general commodities market indices instead of individual commodity prices to better capture the extreme dependence generated by the substitution effect between specific commodities, amplified by recent innovations and environmental concerns. In doing so, we first identified non-parametric mixture copulas that better fit the pair-wise combinations compared with individual copulas. As a novelty, starting from the best-fitted copula, we used a copula-based local Kendall's tau approach to measure nonlinear local dependence in regions between commodities markets. As far as we know, this is the first paper to address this issue, and unlike previous studies' findings, we found asymmetric comovements between energy and metal prices, which tend to become negative at peak returns.

The price co-movements of different categories of commodities belonging to the principal commodities markets (energy, agriculture and metal) have been analysed from various angles and have received special attention following oil price shocks and after the food-price crisis from 2006 to 2008 . These co-movements were attributed to production and transportation costs, increasing demand for biofuels and renewables, and the substitution effect between commodities generated by disruptive technologies, creating a specific mechanism for price transmission (Jiang et al., 2018). The financial channels are at work as well, given the existence of higher returns from commodity prices compared with classic financial assets (Brooks and Prokopczuk, 2013) and the opportunities that they provide for portfolio diversification and hedging risks (Doran and Ronn, 2008; Rafik and Bloch, 2016).

\footnotetext{
${ }^{1}$ According to the Commodities Market Outlook (October 2019), the energy, agriculture and metal commodities markets represent the principal categories of commodities (World Bank, 2019).
} 
Therefore, recent empirical analyses have focussed on price co-movements (e.g., De Nicola et al., 2016; Lucotte, 2016; Pal and Mitra, 2017; Tiwari et al., 2018; Su et al., 2019), or have investigated price-volatility spillovers among energy, agriculture and metal commodities prices (e.g., Aguilera and Radetzki, 2017; Behmiri and Manera, 2015; Fasanya and Akinbowale, 2019; Ji et al., 2018a, 2018b, 2019; Luo and Ji, 2018; Mensi et al., 2014). However, only a few papers have investigated extreme co-movements and have resorted to copula analyses using various families of time-invariant and time-varying individual copula functions (Reboredo, 2012, 2013; Reboredo and Ugolini, 2016; Ji et al., 2018a; Jiang et al., 2018; Yahya et al., 2019). However, these papers have analysed extreme dependence between specific commodity prices (i.e., oil and gold, or oil and biofuels) without considering overall commodities markets. Moreover, copula functions used in previous papers have modelled global dependence structures in energy markets, but could not measure nonlinear local dependence in regions, i.e., copulas might cover useful information on changing trends in the degree of commodities markets' co-movement and in asymmetric co-movement in bear and bull markets.

To overcome this limitation, we first used a novel, copula-based, local dependence framework recently proposed by Huang et al. (2018), which nests the concepts of global dependence and tail dependence. More precisely, we applied the local Kendall's tau based on the mixture copula to identify co-movements and extreme dependencies among agriculture, metal and energy commodities markets that are invisible in a global framework. ${ }^{2}$ Investigating extreme dependencies in regions offers multiple advantages compared with analysing global dependencies. On one hand, investigating local dependencies allows for observing the changing trend of the degree of co-movement between two series. While time-varying copulas allow for analysing the time dynamics of the dependence, they do not identify asymmetries between bull

\footnotetext{
${ }^{2}$ Kendall's tau represents a rank dependence coefficient used to measure dependencies of financial series and can be expressed via copula functions (e.g., Chollete et al., 2009; Rodriguez, 2007).
} 
and bear markets. Huang et al.'s (2018) approach addressed this issue and proposed four classes of local dependence measures along both the main and minor diagonals, respectively. On the other hand, this approach provides more detailed dependence information between commodities markets, as it uncovered the relationship between copula functions and rankbased, local dependence measures. Huang et al.'s (2018) approach is implemented in three steps. We first filtered the data to remove the index returns' serial correlation and conditional heteroskedasticity. To this end, like Huang et al. (2019), we used an ARMA (p, q)-GARH (m, n) model. Second, we investigated global dependencies using individual copulas, accounting for asymmetric and heavy-tail dependencies (i.e., Gumbel, Clayton and rotated Gumbel and Clayton copulas), as well as several two-component mixtures. ${ }^{3}$ In doing so, we applied Zimmer's (2012) approach to mixture copulas, and we found that the best-fitted copula is a mixture between Gumbel and rotated-Gumbel copulas (180 degrees). We also performed a rolling window analysis of the best-mixture copula to see how extreme dependencies evolve over time. Third, starting from this copula function, we computed the empirical local Kendall's tau and drew corresponding theoretical and empirical local dependence surfaces in different regions (upper-upper, lower-lower, upper-lower and lower-upper tails), conducting a series of 5,000 Monte Carlo simulations. As in Huang et al. (2018), we restricted quantiles of our series to the interval $[0.05,0.95]$ to ensure that we had enough observations to calculate the empirical local Kendall's tau. Finally, we ranked commodities markets' dependence structures, and we underlined the advantages of using local dependence measures to investigate extreme comovements in commodities markets.

We also contributed to existing literature by performing an analysis of extreme dependencies and co-movements between general commodities markets, rather than between

\footnotetext{
${ }^{3}$ Huang et al.'s (2018) methodology can be applied to different families of symmetric and asymmetric copula functions, but most previous studies underline the advantages of asymmetric copulas, which led Huang et al. (2018) to estimate theoretical local dependence in the region for Gumbel, Clayton and their rotated versions. Simultaneously, the mixture of these asymmetric copulas in upper and lower tails is viewed as capturing more flexible dependence structures compared with individual copulas (e.g., Hu, 2006).
} 
individual commodities' prices. It is important to capture commodities markets' global dynamics. Indeed, inside each category of commodities (energy, agriculture or metal), each element's price behaviour might record opposite trends in the presence of a substitution effect (e.g., the price of natural gas and coal or the price of copper and aluminium), thereby distorting the analysis of different commodity categories' price transmissions and comovements. Another reason to recommend the use of composite commodities market indices is represented by institutional investors' focus on a broad-based international vehicle, making the investigation of extreme dependencies particularly appealing. For this purpose, we used three composite Rogers International Commodity Indices: Rogers International Commodity Index Energy (RICIE); Rogers International Commodity Index Agriculture (RICIA); and Rogers International Commodity Index Metals (RICIM). The advantages of using these indices can be found in their ability to characterise overall commodities markets by considering 38 commodity futures contracts' prices using different weights (e.g., crude oil futures prices represent $37.50 \%$ of RICIE, while natural gas prices represent $15 \%$; gold represents $19.92 \%$ of RICIM, while aluminium represents $15.93 \%$; and corn prices represent $13.61 \%$ of RICIA, whereas cotton represents $12.03 \%) .{ }^{4}$ At the same time, these indices' composition is viewed as more stable compared with that of other commodity indices, increasing the transparency for making investment decisions. Finally, and most importantly, these indices are constructed based on futures prices rather than spot prices. ${ }^{5}$ As far as we know, Kang et al. (2017) and Liu et al. (2019) are the only papers that have addressed the dynamic spillover among commodities markets by using futures contract prices.

The last contribution to the literature is represented by a portfolio analysis that examined pairs of commodity indices. Starting with Engle's (2002) time-varying dynamic

\footnotetext{
${ }^{4}$ http://www.rogersrawmaterials.com/documents/RICIHndbk_01.31.19.pdf

${ }^{5}$ Investigating the co-movement and extreme dependencies between futures prices has multiple advantages, as it allows for the mitigation of stale quotes and non-synchronous problems in the spot markets, while noise in futures prices is constant on average (for a detailed discussion, please refer to Albulescu et al., 2017).
} 
conditional correlation (DCC) model, we computed hedge ratios following Kroner and Sultan (1993). Afterward, we used conditional volatilities to construct optimal portfolio weights, using Kroner and Ng's (1998) approach.

To preview our findings, we showed that co-movements increase in extreme situations for all pairs of commodity indices, a result of agreement with previous findings reported in the literature. However, unlike other studies, we found a stronger dependence at lower tails for the energy pairs of indices. In addition, for the agriculture-metal pair, we reported a ' $\mathrm{V}$ type' local dependence. Furthermore, the three-dimensional Kendall's tau plot for upper tails in quantiles shows asymmetric co-movements for the energy-metal pair, which becomes negative at peak returns. Finally, we documented the existence of hedging and portfolio diversification opportunities among energy, agriculture and metal commodities markets.

The rest of the paper is organised as follows: Section 2 presents the literature review on commodity price co-movements; Section 3 addresses the methodology; Section 4 presents the data and marginal model results; Section 5 describes the copula results; and Section 6 provides the general and copula-based local dependence plots. The last section concludes the paper.

\section{Literature review}

The extensive literature addressing the co-movements and dependencies between commodities markets usually has focussed on individual commodity prices and has resorted to linear and non-linear cointegration techniques or volatility spillover analyses (Aguilera and Radetzki, 2017; Avalos, 2014; Baumeister and Kilian, 2014; Behmiri and Manera, 2015; Bildirici and Turkmen. 2015; Chen et al., 2010; Choi and Hammoudeh, 2010; De Nicola et al., 2016; Ewing and Malik, 2013; Fowowe, 2016; Hammoudeh and Yuan, 2008; Hassouneh et al., 2012; Ji et al., 2018b; Liu et al., 2017; Lucotte, 2016; Natanelov et al., 2011; Nazlioglu 
and Soytas, 2012; Pal and Mitra, 2017; Rezitis, 2015; Saghaian, 2010; Su et al., 2019). Most of these works have documented increased co-movements and volatility spillovers between energy and other commodity prices (Du et al., 2011; Fasanya and Akinbowale, 2019; Ji and Fan, 2012; Serra, 2011; Lucotte, 2016; Natanelov et al., 2011; Nazioglu et al., 2013; Mensi et al., 2014; Su et al., 2019; Zhang and Qu, 2015).

Nevertheless, only a few papers have addressed extreme co-movements and dependencies on commodities markets by resorting to copula functions (e.g., Ji et al., 2018a; Jiang et al., 2018; Liu et al., 2019; Reboredo, 2012; Reboredo, 2013; Reboredo and Ugolini, 2016; Yahya et al., 2019). The first paper in this grouping is Reboredo (2012), who investigated the dependencies between oil and food prices using conditional and time-varying copulas, and reported the absence of extreme dependencies. With an emphasis on extreme dependencies between the energy and metal markets, and using weekly data from 2000 to 2011, Reboredo (2013) examined the possibility that gold might represent a hedge against oil price volatility and documented a significant average dependence between gold and oil. However, Reboredo (2013) demonstrated the existence of tail independence between the two markets, stating that gold might be viewed as a safe haven against extreme oil price fluctuations. In the same spirit, Reboredo and Ugolini (2016) underlined oil price shocks' role in explaining volatility in metal prices. Their results indicated that large downward and upward movements in oil prices generate asymmetric spillovers into the metal market.

More recent studies have turned to time-varying or regime-switching copulas to investigate dependencies between energy and other commodity prices. Likewise, by adopting a time-varying copula with a switching dependence, Ji et al. (2018a) demonstrated that agriculture commodities are more sensitive to oil price shocks than gas price shocks. In the same vein, Liu et al. (2019) turned to Markov-switching GRG mixture copulas to study dependencies between oil and agriculture futures prices in both non-extreme and extreme 
conditions. For most examined agriculture commodities, the authors reported positive extreme and non-extreme co-movements with oil futures prices. Jiang et al. (2018) and Yahya et al. (2019) combined time-frequency decomposition of commodity price series with copula functions to study extreme dependencies among energy, agriculture and metal commodities prices. Both papers documented an increased tail dependence during and after the recent global crisis.

Nevertheless, all previous papers modelled commodities prices' global dependence structure, thereby focussing on asymmetric co-movements and changing trends in comovements in bear and bull markets. Therefore, we added to this narrow literature strand and, unlike studies that used individual time-invariant and time-varying copulas, we used a mixture of copulas to explain commodities markets' extreme dependencies more clearly, considering asymmetries in both upper and lower tails. Furthermore, to gain additional information about extreme co-movements in the upper and lower tails, we used a local dependence measure based on the Kendall's tau, which combines global and tail dependence. This way, we could see whether extreme dependencies are symmetric in bear markets, bull markets or both climates. In addition, unlike existing studies, we examined general commodities markets' indices, not individual prices, while focussing on futures instead of spot prices, for the reasons mentioned in the previous section.

\section{Methodology}

Copulas represent multivariate (joint) distribution functions that require uniform univariate marginal distributions. Therefore, in line with previous papers (i.e., Reboredo, 2012, 2013), in the first step, we used an ARMA (p, q)-GARCH (m, n) model with skewed tdistribution to remove the serial correlation and conditional heteroskedasticity in all index return series. In the second step, we used individual copula functions that allowed for an 
investigation of asymmetric dependencies in both upper and lower tails (e.g., Gumbel and Clayton), and we compared their performance with a mixture of functions. Finally, starting from the copulas that better fit the pair-wise combinations, we constructed the copula-based local Kendall's tau plots to assess local dependencies between commodities markets. ${ }^{6}$

\subsection{Copula functions}

Given the data properties that exhibit asymmetries and heavy tails, we used the Gumbel copula, which displays upper-tail dependence; the Clayton copula, which displays lower-tail dependence; their rotated versions; and their mixture.

The bivariate Gumbel copula $\left(C_{G}\right)$ is expressed as:

$C_{G}(u, v ; \alpha)=\exp \left(-\left[(-\log (u))^{\alpha}+(-\log (v))^{\alpha}\right]^{1 / \alpha}\right.$,

in which $\alpha \in[1,+\infty]$. When $\alpha \rightarrow+\infty$, the variables exhibit more dependence.

The rotated Gumbel copula at 180 degrees $\left(C_{r G}\right)$ is:

$C_{r G}(u, v ; \alpha)=\mathrm{u}+v-1+C_{G}(1-u, 1-v ; \alpha)$,

in which $\alpha \in[1,+\infty]$. In this case, if $\alpha \rightarrow 1$, the two variables are independent.

The Clayton copula $\left(C_{C L}\right)$ showed asymmetry, as the degree of dependence in the lower tail is higher than in the upper tail:

$C_{C L}(u, v ; \theta)=\left[\max \left(u^{-\theta}+v^{-\theta}-1,0\right]^{-1 / \theta}\right.$,

in which $\theta \in[-1,0] \backslash\{0\}$ and larger values of $\theta$ indicate strong dependence.

The rotated Clayton copula $\left(C_{r C L}\right)$ only showed lower tail dependence. Like $C_{C L}$, larger values of $\theta$ indicate strong dependence:

$C_{r C L}(u, v ; \theta)=\mathrm{u}+v-1+C_{C L}(1-u, 1-v ; \theta)$.

Building on Zimmer (2012) and Huang et al. (2018), we defined the mixture of four individual copulas as follows:

$C_{\text {mix } 1}(\cdot)=\varphi * C_{G}(\cdot)+(1-\varphi) * C_{C L}(\cdot)$,

\footnotetext{
${ }^{6}$ Huang et al.'s (2018) nonlinear dependence in region can be applied not only to the Kendall's tau, but also to the Spearman's rho dependence measure, with similar results.
} 
$C_{\text {mix } 2}(\cdot)=\varphi * C_{r G}(\cdot)+(1-\varphi) * C_{r C L}(\cdot)$,

$C_{m i x 3}(\cdot)=\varphi * C_{G}(\cdot)+(1-\varphi) * C_{r G}(\cdot)$,

$C_{\text {mix } 4}(\cdot)=\varphi * C_{C L}(\cdot)+(1-\varphi) * C_{r C L}(\cdot)$,

in which $\varphi \in(0,1)$ is an estimable parameter that indicates the first copula's proportional contribution to the mixture.

\subsection{General chi-plots for dependence identification}

The dependency pattern between two series can by identified by using chi-plots, which are estimated based on the joint distribution $(H)$ of copulas and show the shape of this joint distribution. Following Fisher and Switzer (1985), we generated a scatter plot for each pair of indices $\left(\lambda_{i}, \chi_{i}\right)$ based on:

$\lambda_{i}=4 S_{i} \max \left\{\left(F_{i}-\frac{1}{2}\right)^{2}\left(G_{i}-\frac{1}{2}\right)^{2}\right\}$ and

$\chi_{i}=\frac{H_{i}-F_{i} G_{i}}{\left\{F_{i}\left(1-F_{i}\right) G_{i}\left(1-G_{i}\right)\right\}^{0.5}}$,

in which $\lambda_{i}$ is a measure of distance from the center of the data set of the data point $\left(X_{k}, Y_{k}\right)$, $H_{i}=\sum_{k \neq i} \frac{I\left(X_{k} \leq X_{i} ; Y_{k} \leq Y_{i}\right)}{n-1}, F_{i}=\sum_{k \neq i} \frac{I\left(X_{k} \leq X_{i}\right)}{n-1}, G_{i}=\sum_{k \neq i} \frac{I\left(Y_{k} \leq Y_{i}\right)}{n-1}$ and $S_{i}=\operatorname{sign}\left\{\left(F_{i}-\frac{1}{2}\right)\left(G_{i}-\right.\right.$ $\left.\left.\frac{1}{2}\right)\right\}$

\subsection{Copula-based local Kendall's tau plots}

The copula-based formula for the global Kendall's tau (Schweizer and Wolf, 1981) for two variables $X$ and $Y$ is:

$\tau(X, Y)=4 \int_{0}^{1} \int_{0}^{1} C(u, v) d C(u, v)-1$.

For two variables, $X$ and $Y$, with $p$ and $q$ as their quantiles, the novel tail dependence measures on local Kendall's tau, developed by Huang et al. (2018), are:

$$
\begin{aligned}
& \lambda_{U U}^{\text {Kendall }}=\lim _{p \rightarrow 1} \lambda_{U U}^{\text {Kendall }}(X, Y ; p, p), \\
& \lambda_{U L}^{\text {Kendall }}=\lim _{p \rightarrow 1} \lambda_{U L}^{K \text { Endall }}(X, Y ; p, 1-p),
\end{aligned}
$$


$\lambda_{L U}^{\text {Kendall }}=\lim _{p \rightarrow 0} \lambda_{L U}^{\text {Kendall }}(X, Y ; p, 1-p)$,

$\lambda_{L L}^{\text {Kendall }}=\lim _{p \rightarrow 0} \lambda_{U U}^{\text {Kendall }}(X, Y ; p, p)$

in which $\lambda_{U U}^{\text {Kendall }}, \lambda_{U L}^{\text {Kendall }}, \lambda_{L U}^{\text {Kendall }}$ and $\lambda_{L L}^{\text {Kendall }}$ are the upper-upper, upper-lower, lowerupper and lower-lower tail dependence measures based on the local Kendall's tau.

\section{Data and filtering results}

\subsection{Data sample}

The Rogers International Commodity Indices (RICI) represent commodity composite futures price indices that reflect price dynamics and expectations for energy, agriculture and metal commodities markets. According to the RICI Handbook (Rogers International Commodity Indices, 2019), for futures contracts, the indices roll over three days and are rebalanced monthly. RICI includes 38 commodities futures contracts: six for the energy index RICIE; 22 for the agriculture commodity index RICIA; and 10 for the metal index RICIM. ${ }^{7}$

Our daily data were obtained from the Quandl database and cover the period 3 January 2005 to 1 August 2018. Table 1 summarises general statistics from the log returns of three indices (dlnRICIA, dlnRICIE and dlnRICIM). The average returns were positive, but close to zero, except for the RICIM index, while greater volatility was observed for RICIE. The high kurtosis indicated the presence of extreme values in our series, especially in the case of the energy index. The Jarque-Bera test for the unconditional distribution's normality strongly rejected the normality for all three series. The unit root tests ADF, PP, and KPSS indicated that all three series are stationary.

[Insert Table 1 about here]

Figures $1 \mathrm{a}, 1 \mathrm{~b}$ and $1 \mathrm{c}$ show the indices and their log returns' dynamics. It seems that RICIA and RICIM followed similar patterns, while RICIE did not exhibit the upward trend

\footnotetext{
${ }^{7}$ More details about each commodity's weight inside the market index and futures contracts can be found at http://www.rogersrawmaterials.com/documents/RICIHndbk_01.31.19.pdf.
} 
unregistered by the other two indices in 2011. During the final period of 2014, the RICIA and RICIE values decreased, while the RICIM index showed a slight increase after 2016.

[Insert Figure 1 about here]

\subsection{Marginal model results}

Several ARMA (p, q)-GARH (m, n) marginal models were tested. For all our indices, the best filtering measure was an ARMA $(1,0)-\mathrm{GARCH}(2,1)$ model. The results reported in Table 2 show that the autocorrelation and the conditional heteroskedasticity for all three series were removed according to Ljung-Box and ARCH statistics. Our evidence indicates that the AR term is insignificant for RICIA.

[Insert Table 2 about here]

\section{Copula results}

\subsection{Individual and mixture copulas}

In what follows, we present a comparison between the results from the individual (Table 3) and mixture copulas proposed in Equations (5)-(8) (Table 4). According to the information criteria (LR, AIC, BIC), in the case of individual copulas, the rotated Gumbel performed better among all commodity pairs, showing asymmetric co-movements that are more important for lower tails. For all commodities pairs (RICIA-RICIM, RICIA-RICIE and RICIM-RICIE), our findings show that mixture copulas perform better than individual copulas, according to all information criteria that we use.

[Insert Table 3 about here]

We observe in Table 4 that the best copula mixture model for all commodities pairs is $C_{\text {mix } 3}(\cdot)$, namely a combination between the Gumbel and rotated Gumbel copulas. For the RICIA-RICIM and RICIM-RICIE pairs, the Gumbel copula $(\varphi)$ weight is $24.8 \%$ and $29.1 \%$, 
respectively, while the RICIA-RICIE pair demonstrate the Gumbel copula weight at $40.3 \%$. This evidence of asymmetry (especially for the RICIA-RICIM and RICIM-RICIE comovements) shows that the rotated Gumbel copula has the largest weight in the mixture (i.e., 75.2\% for the RICIA-RICIM pair). Therefore, we noted an increased dependence in both upper and lower tails, with co-movements in the lower tails being more important (comovements are higher during crisis periods).

[Insert Table 4 about here]

For the RICIM-RICIE pair, our copula findings differ from those reported by Reboredo and Ugolini (2016), who noticed that spillovers from upward oil price movements into metal prices are larger than for downward oil price spillovers. For the RICIA-RICIE pair, extreme downward oil price movements exert a negative effect on agriculture commodity prices. Our results validate the production-cost channels and contrast with results from Reboredo (2012), who reported no extreme market dependence between oil and food prices, indicating neutrality in agriculture commodities markets, especially before 2008. The evidence of asymmetric dependencies between oil and agriculture prices demonstrates the need to examine oil prices' asymmetric effect on the stabilisation of food prices.

\subsection{Best mixture copula rolling analysis}

To gain further insights on commodities markets' extreme co-movements, we performed a rolling window analysis (500 days) of the best copula mix $\left(C_{\operatorname{mix} 3}(\cdot)\right)$ to observe how dependencies fluctuate over time. ${ }^{8}$ To this end, starting from the coefficients' standard errors, we generated confidence intervals at levels of 5\%. Figure 2 presents the results for all pairs of indices.

[Insert Figure 2 about here]

\footnotetext{
${ }^{8}$ This rolling window corresponds roughly to two years of trading days. Bai et al. (2018) used a similar rolling window in their analysis and underlined the advantages of using lengthy windows in copula analysis.
} 
Figure 2a shows that with the RICIA-RICIM pair, the extreme dependencies predominantly are explained by the rotated Gumbel copula, which has a higher weight in the mixture copula. Therefore, for the 2007-2017 period, co-movements between the agriculture and metal commodities markets are more important in lower tails. A different pattern surfaced starting in 2018, when asymmetric co-movements generally were stronger in upper tails.

In the case of the RICIA-RICIE pair (Figure 2b), the extreme dependencies are stronger and better explained by the rotated Gumbel copula, which clearly carries greater weight in the mixture. The exception is for the final period in 2015, when the Gumbel copula became dominant. These results show that the period after the Global Financial Crisis was characterised by higher dependencies in lower tails, while the recent period is characterised by asymmetric co-movements that increased in the upper tails. Finally, Figure $2 \mathrm{c}$ shows that from 2007 to 2015, the Gumbel and rotated Gumbel in the mixture exerted no clear dominance, indicating asymmetric and extreme co-movements in both bull and bear markets. Nevertheless, for the final period, the extreme dependencies are explained predominantly by the Gumbel copula.

However, the true parameter values (Figure 2) do not explain the dependencies' intensity over time. Therefore, we proceeded to a transformation of true values in Kendall's tau values (Figure 3). As in the previous case, we noticed a relative dominance in the rotated Gumbel copula during the sample's first period. Starting with 2016, for all commodity pairs, we observed a dominance in the Gumbel copula, i.e., the extreme dependencies manifested particularly in the upper tails. When we analysed the dynamics of the mixture copula $\left(C_{\text {mix } 3}(\cdot)\right)$ for the RICIA-RICIM pair (Figure 3a), we noticed an increased dependence between agriculture and metal markets after the Global Financial Crisis (2010 to 2015). A similar result was obtained for the RICIM-RICIE pair of commodities (Figure 3c). However, extreme dependence cycles were observed for the RICIA-RICIE pair over the entire analysed period. 
This evidence shows that in the case of the energy-agriculture pair of indices, the extreme comovements manifest independently of the economic context. Consequently, the stabilisation of energy prices (i.e., oil prices) exerts an important effect on the stabilisation of agriculture and food prices.

[Insert Figure 3 about here]

\section{General and copula-based local dependence plots}

\subsection{General chi-plot results}

The chi-plots show that all pairs of commodity indices exhibit heavy-tail dependence, given that most distribution points are plotted beyond the control lines (+/- 0.05). Figure 4 also shows that the extreme dependencies are positive (an increase in one index price is associated with an increase in the price of the corresponding pair), but they are asymmetric. However, the general chi-plots do not allow details of the dependencies to be seen, namely if an asymmetric local dependence pattern or asymmetry in both upper and lower tails is found.

[Insert Figure 4 about here]

\subsection{Copula-based local Kendall's tau results}

To compare the properties of the global and local Kendall's tau based on $C_{m i x 3}(\cdot)$, we first computed the corresponding theoretical and empirical local dependence surfaces in different regions, performing Monte Carlo simulations for the product copula (with a sample size of 5,000 observations) for each pair of commodities (see Figures A1-A3 in Appendix A) and demonstrating their relationship. For all commodity pairs, the first two plots (Figures A1A3) indicate that local Kendall's tau based on $C_{m i x 3}(\cdot)$ copula shows significant asymmetric characteristics along the main diagonal.

Following this, we compared global and local dependence co-movements' properties using copula-based Kendall's tau plots (Figure 5). Starting from Equations (12)-(15), we 
computed the theoretical global and local Kendall's tau and observed no noticeable difference between the global theoretical and empirical Kendall's tau, indicating that global dependence may cover extreme co-movements. Based on the local Kendall's tau for all commodity pairs, we noticed increased co-movements in extreme situations, i.e., in the lower and upper quantiles. For all commodity pairs, the local dependence in bull markets is obviously smaller than their local dependence in bear markets, exhibiting an asymmetric local dependence pattern. This result is consistent with findings reported in earlier literature, underlining the contagion phenomenon in crisis times (Yahya et al., 2019). We noticed a stronger dependence at lower tails in indices' energy pairs and a 'V-type' local dependence in the agriculture-metal commodity pair. In contrast with Jiang et al. (2018), we found that tail dependence changes over time. These results indicate that the energy market is more connected with other commodities markets during periods of financial stress. At the same time, extreme dependencies between agriculture and metal commodities indices manifest during both bull and bear markets.

[Insert Figure 5 about here]

Given the existence of a stronger dependence in the lower and upper tails, we constructed three-dimensional Kendall's tau plots for these in quantiles for each commodity pair (Figure 6). For the RICIA-RICIM pair, the results show that the extreme dependencies in the lower tails are higher (Figure 6b) and, as expected, symmetric, while the extreme dependencies in the upper tails are asymmetric (Figure 6a). This represents an original result that demonstrates symmetry and asymmetry are not only between upper and lower tails, but also inside upper and lower tails. This result's economic intuition is simple and might be explained by economic mechanisms. In bear markets, when global demand diminishes, the price of industrial metals decreases. This is equivalent to a reduction in production costs for 
agriculture commodities. However, in bull markets, speculation reasons might explain asymmetric co-movements between agriculture and metal commodities markets.

[Insert Figure 6 about here]

Similar findings are reported for the RICIA-RICIE pair of indices, although the comovements are not as strong. The extreme asymmetric dependence recorded in the upper tails can be associated with the substitution effect between energy and agriculture commodities, initially induced by the dominance of synthetic fibres, rubber, fertilizers and plastics, which have replaced natural materials. The rise of environmental concerns reversed this trend in recent years.

A slightly different situation is seen for the RICIM-RICIE pair of indices, in which the upper tails' co-movements are asymmetric and tend to become negative for the peak returns (Figure 6e). The negative dependencies can be explained by technological innovations (e.g., fibre-optic lines replacing copper cables, which are tied to the petrochemical industry). Two implications arise from this evidence. First, the dependencies between energy and metal markets reinforce energy prices' impact on inflation, given that oil and gold are leading indicators for general price levels (Bildirici and Turkmen, 2015). Second, negative and asymmetric co-movements in the upper tails between energy and metal prices show that precious metals, such as gold, can represent a hedge against inflation for extreme, upper-tail values. Thus, our findings complement the results reported by Aye et al. (2016), who also viewed gold as an inflation hedge in the long run.

Overall, these findings confirm the mixture of copula results and reinforce related literature in offering information about a more extensive dependence in quantiles. Our results show that commodities markets' extreme dependencies are very complex and manifest differently for specific commodity indices, revealing commodity prices' asymmetric behaviour, especially for the upper tails. 
To better underline our findings' importance, we performed a simple portfolio analysis whose results should be viewed with caution, given the documented asymmetries that characterise commodities markets' co-movements in extreme situations. In fact, copulas represent alternative methods to analyse portfolio risk in bull and bear markets, and do not assume risk factors that are distributed normally, as classic portfolio analyses do.

\section{A classic portfolio analysis}

For the portfolio analysis, like Sadorsky (2012), we used Engle's (2002) time-varying DCC model, with the correlation estimator $(\rho)$ :

$\rho_{i j, t}=\frac{q_{i j, t}}{\sqrt{q_{i i, t} q_{j j, t}}}$

The summary statistics of dynamic correlations are presented in Table 5 and show no important differences in terms of correlations between our pairs of indices.

[Insert Table 5 about here]

Starting from the computed conditional volatilities, we constructed, in a second step, hedge ratios using Kroner and Sultan's (1993) approach and optimal portfolio weights following Kroner and $\mathrm{Ng}(1998)$.

\subsection{Hedge ratios}

The hedge ratio $(\beta)$ proposed by Kroner and Sultan (1993) shows how a long position in the asset $i$ can be hedged by a short position in the asset $j$ :

$\beta_{i j, t}=\frac{h_{i j, t}}{h_{j j, t}}$

in which $h_{i j, t}$ is the conditional covariance between assets $i$ and $j$.

The results are presented in Table 6 and show that the average hedge ratio between RICIA (long position) and RICIM (short position) is 0.42 . This means that a $\$ 1$ long position 
in RICIA can be hedged for 42 cents with a short position in RICIM. The average hedge ratio between RICIE and RICIA is 0.67 , meaning that a $\$ 1$ long position in the energy market can be hedged for a 67 -cent short position in the agriculture market.

[Insert Table 6 about here]

\subsection{Portfolio weights}

Kroner and Ng's (1998) approach is employed to design optimal portfolio weights $(w)$. For two assets, $w_{i j, t}$ represents the weight of the asset $i$ in the $\$ 1$ portfolio of two assets $i$ and $j$ (therefore, the weight of the asset $j$ is $1-w_{i j, t}$ ):

$w_{i j, t}=\frac{h_{j j, t}-h_{i j, t}}{h_{i i, t}-2 h_{i j, t}+h_{j j, t}}$.

For example, Table 7 indicates that the average weight between RICIA and RICIE is 0.84 , i.e., for a $\$ 1$ portfolio optimisation, 84 cents should be invested in the agriculture commodity index, whereas 16 cents should be invested in the energy commodity index. Furthermore, if we consider the RICIM/RICIE pair, for a $\$ 1$ portfolio optimisation, 69 cents should be invested in RICIM and 31 cents in RICIE. Therefore, we can conclude that agriculture and metal commodities markets can offer some portfolio diversification opportunities for the energy commodities market.

[Insert Table 7 about here]

\section{Conclusions}

Using a copula-based local Kendall's tau approach, this study investigated local dependencies and co-movements among energy, agriculture and metal commodities markets, relying on RICI indices over the 3 January 2005 to 1 August 2018 period (daily data). More precisely, we showed that a Gumbel and rotated Gumbel copula mixture better fit the pairwise combinations for all commodity pairs. Therefore, we posit that dependence structure is 
asymmetric and exhibits both high- and low-tail dependence, with the low-tail dependence being stronger. We also showed that the novel copula-based local Kendall's tau approach offers a deeper understanding of extreme dependencies compared with the global approach.

Specifically, we noticed that in indices' energy pairs, a stronger dependence at lower tails exists, while in the agriculture-metal pair, we reported a 'V-type' local dependence, in which extreme co-movements are higher in both the upper and lower tails. This behaviour is explained by the complementarity between agriculture and metal markets. When food demand increases, the production process in the agriculture field follows a similar process, triggering an increase in metal prices. At the same time, if we consider the case of the recent food crisis from 2007 and 2008, when agriculture commodities' prices increased dramatically, we noticed that we recorded similar dynamics in precious metals' prices.

In contrast to previous essays on commodities market co-movements, we demonstrated that the extreme upper-tail dependencies between energy and metal commodities markets are asymmetric and negative for high returns. This result is explained by the substitution effect existing between energy and metal commodities, amplified lately by the appearance of disruptive technologies implemented in the electricity generation and vehicle industries.

Our findings reveal some complex and extreme dependencies among agriculture, energy and metal markets and should be of value to those in the field, particularly financial investors and risk managers. Although during periods of financial stress, the energy market does not offer a good option for portfolio diversification, during financial booms, the extreme comovements between energy and metal commodities markets become negative and highlight the potential for portfolio diversification.

Finally, it is important to realise that the extreme co-movements between energy and agriculture markets manifest for the entire time horizon, while the local dependencies between energy and metal markets mainly are recorded during bull and bear markets. The agriculture 
and metal markets offer portfolio diversification opportunities for investors in the energy futures market.

Generally, in bull and bear markets, results from classic portfolio and risk management analyses that require normally distributed factors are misleading, and the global copula investigations only allow for the identification of asymmetries between upper and lower tails. Nevertheless, we showed that commodities markets' co-movements are asymmetric in both bull and bear markets, and specific to each pair of commodities. For example, we showed that for the RICIA-RICIM pair, the extreme dependencies in upper tails are weaker compared with those recorded in lower tails, but are asymmetric. Another original result is that reported for the RICIM-RICIE pair, in which the asymmetric co-movements became negative at peak returns.

\section{Acknowledgements}

This work was supported by a grant of the Romanian National Authority for Scientific Research and Innovation, CNCS-UEFISCDI, project number PN-III-P1-1.1-TE-2016-0142. Supports from the National Natural Science Foundation of China under Grant No. 71974181, No. 71774152, and Youth Innovation Promotion Association of Chinese Academy of Sciences (Grant: Y7X0231505) are equally acknowledged.

\section{References}

Aguilera, R.F. and M. Radetzki. 2017. The synchronized and exceptional price performance of oil and gold: Explanations and prospects. Resources Policy 54: 81-87.

Albulescu, C.T., Goyeau, D. and A.K. Tiwari. 2017. Co-movements and contagion between international stock index futures markets. Empirical Economics 52: 1529-1568. 
Avalos, F. 2014. Do oil prices drive food prices? The tale of a structural break. Journal of International Money and Finance 42: 253-271.

Aye, G.C., Chang, T. and R. Gupta. 2016. Is gold an inflation-hedge? Evidence from an interrupted Markov-switching cointegration model. Resources Policy 48: 77-84.

Bai, Y., Dang, Y., Park, C. and T. Lee. 2018. A rolling analysis on the prediction of value at risk with multivariate GARCH and copula. Communications for Statistical Applications and Methods 25: 605-618.

Baumeister, C. and L. Kilian. 2014. Do oil price increases cause higher food prices? Economic Policy 29: 691-747.

Behmiri N.B. and M. Manera. 2015. The role of outliers and oil price shocks on volatility of metal prices. Resources Policy 46: 139-150.

Bildirici, M.E. and C. Turkmen. 2015. Nonlinear causality between oil and precious metals. Resources Policy 46: 202-211.

Brooks, C. and M. Prokopczuk. 2013. The dynamics of commodity prices. Quantitative Finance, 13: 527-542.

Chen, S., Kuo, H. and C. Chen. 2010. Modeling the relationship between the oil price and global food prices. Applied Energy 87: 2517-2525.

Chollete, L., Heinen, A. and A. Valdesogo. 2009. Modeling international financial returns with a multivariate regime-switching copula. Journal of Financial Econometrics 7: $437-480$.

Choi, K. and S. Hammoudeh. 2010. Volatility behavior of oil, industrial commodity and stock markets in a regime switching environment. Energy Policy 38: 4388-4399.

De Nicola, F., De Pace, P. and M.A. Hernandez. 2016. Co-movement of major energy, agricultural, and food price returns: A time-series assessment. Energy Economics 57: $28-41$. 
Doran, J.S. and E.I. Ronn. 2008. Computing the market price of volatility risk in the energy commodity markets. Journal of Banking and Finance 32: 2541-2552.

Du, X., Yu, C.L. and D.J. Hayes. 2011. Speculation and volatility spillover in the crude oil and agricultural commodity markets: A Bayesian analysis. Energy Economics 33: 497-503.

Engle, R.F. 2002. Dynamic conditional correlation: a simple class of multivariate generalized autoregressive conditional heteroskedasticity models. Journal of Business \& Economic Statistics 20: 339-350.

Ewing, B.T. and F. Malik. 2013. Volatility transmission between oil and gold futures under structural breaks. International Review of Economics and Finance 25: 113-121.

Fasanya, I. and S. Akinbowale. 2019. Modelling the return and volatility spillovers of crude oil and food prices in Nigeria. Energy 169: 186-205.

Fisher, N.I. and P. Switzer. 1985. Chi-plots for assessing dependence. Biometrika 72: 253265.

Fowowe, B. 2016. Do oil prices drive agricultural commodity prices? Evidence from South Africa. Energy 104: 149-157.

Hammoudeh, A. and Y. Yuan. 2008. Metal volatility in presence of oil and interest rate shocks. Energy Economics 30: 606-620.

Hassouneh, I., Serra, T., Goodwin, B.K. and J.M. Gil. 2012. Non-parametric and parametric modeling of biodiesel, sunflower oil, and crude oil price relationships. Energy Economics 34: 1507-1513.

Hu, L. 2006. Dependence patterns across financial markets: A mixed copula approach. Applied Financial Economics 16: 717-729. 
Huang, Z., de la Peña, V. H. and L. Chollete. 2018. Copula-based local dependence framework with application to co-movements between international stock markets. Available at: http://www.huangzaixin.com/papers/Manuscript.pdf.

Ji, Q., Bouri, E., Roubaud, D. and S.J.H. Shahzad. 2018a. Risk spillover between energy and agricultural commodity markets: A dependence-switching CoVaR-copula model. Energy Economics 75:14-27.

Ji, Q., Bouri, E. and Roubaud, D. 2018b. Dynamic network of implied volatility transmission among US equities, strategic commodities, and BRICS equities. International Review of Financial Analysis 57: 1-12.

Ji, Q., Bouri, E., Roubaud, D. and Kristoufek, L. 2019. Information interdependence among energy, cryptocurrency and major commodity markets. Energy Economics, 81, 10421055.

Ji, Q. and F. Fan. 2012. How does oil price volatility affect non-energy commodity markets? Applied Energy 89: 273-280.

Jiang, Y., Lao, J., Mo, B. and H. Nie. 2018. Dynamic linkages among global oil market, agricultural raw material markets and metal markets: An application of wavelet and copula approaches. Physica A: Statistical Mechanics and its Applications 508: 265279.

Jiang, Y., Jiang, C., Nie, H. and B. Mo. 2019. The time-varying linkages between global oil market and China's commodity sectors: Evidence from DCC-GJR-GARCH analyses. Energy 166: 577-586.

Kang, S. H., McIver, R. and S-M. Yoon. 2017. Dynamic spillover effects among crude oil, precious metal, and agricultural commodity futures markets. Energy Economics Energy Economics 62: 19-32. 
Kroner, K.F. and V.K. Ng. 1998. Modeling asymmetric movements of asset prices. Review of Financial Studies 11: 817-844.

Kroner, K.F. and J. Sultan. 1993. Time dynamic varying distributions and dynamic hedging with foreign currency futures. Journal of Financial and Quantitative Analysis 28: $535-551$.

Liu, X., Zhang, S. and J. Bae. 2017. The nexus of renewable energy-agriculture-environment in BRICS. Applied Energy 204: 489-496.

Liu, X., Pan, F., Yuan, L. and Y. Chen. 2019. The dependence structure between crude oil futures prices and Chinese agricultural commodity futures prices: Measurement based on Markov-switching GRG copula. Energy 182: 999-1012.

Lucotte, Y. 2016. Co-movements between crude oil and food prices: A post-commodity boom perspective. Economics Letters 147: 142-147.

Luo, J. and Q. Ji. 2018. High-frequency volatility connectedness between the US crude oil market and China's agricultural commodity markets. Energy Economics 76, 424438.

Mensi, W., Beljid, M., Boubaker, A. and S. Managi. 2013. Correlations and volatility spillovers across commodity and stock markets: linking energies, food and gold. Economic Modelling 32: 15-22.

Mensi, W., Hammoudeh, S., Nguyen, D.K. and S.-M. Yoon. 2014. Dynamic spillovers among major energy and cereal commodity prices. Energy Economics 43: 225-243.

Natanelov, V., Alam, M.J., McKenzie, A.M. and G. Van Huylenbroeck. 2011. Is there comovement of agricultural commodities futures prices and crude oil? Energy Policy 39: 4971-4984.

Nazlioglu, S., Erdem, C. and U. Soytas. 2013. Volatility spillover between oil and agricultural commodity markets. Energy Economics 36: 658-665. 
Nazlioglu, S. and U. Soytas. 2012. Oil price, agricultural commodity prices, and the dollar: A panel cointegration and causality analysis. Energy Economics 34: 1098-1104.

Pal, D. and S.K. Mitra. 2018. Interdependence between crude oil and world food prices: A detrended cross correlation analysis. Physica A 492: 1032-1044.

Pal, D. and S.K. Mitra. 2017. Time-frequency contained co-movement of crude oil and world food prices: A wavelet-based analysis. Energy Economics 62: 230-239.

Rafiq, S. and H. Bloch. 2016. Explaining commodity prices through asymmetric oil shocks: Evidence from nonlinear models. Resources Policy 50: 34-48.

Reboredo, J.C. 2012. Do food and oil prices co-move? Energy Policy 49: 456-467.

Reboredo, J.C. 2013. Is gold a hedge or safe haven against oil price movements? Resources Policy 38: 130-137.

Reboredo, J.C. and A. Ugolini. 2016. The impact of downward/upward oil price movements on metal prices. Resources Policy 49: 129-141.

Rezitis, A.N. 2015. The relationship between agricultural commodity prices, crude oil prices and US dollar exchange rates: a panel VAR approach and causality analysis. International Review of Applied Economics 29: 403-434.

Rodriguez, J.C. 2007. Measuring financial contagion: A copula approach. Journal of Empirical Finance 14: 401-423.

Rogers International Commodity Index. 2019. RICI® Handbook. 30 January. Available at: http://www.rogersrawmaterials.com/documents/RICIHndbk_01.31.19.pdf.

Sadorsky, P. 2012. Correlations and volatility spillovers between oil prices and the stock prices of clean energy and technology companies. Energy Economics 34: 248-255.

Saghaian, S.H., 2010. The impact of the oil sector on commodity prices: correlation or causation? Journal of Agricultural and Applied Economics 42: 477-485. 
Schweizer, B. and E.F. Wolf. 1981. On nonparametric measures of dependence for random variables. Annals of Statistics 9: 879-885.

Serra, T. 2011. Volatility spillovers between food and energy markets: A semiparametric approach. Energy Economics 33: 1155-1164.

Su, C.W., Wang, X.Q., Tao, R. and O.R. Lobont. 2019. Do oil prices drive agricultural commodity prices? Further evidence in a global bio-energy context. Energy 172: 691-701.

Tiwari, A.K., Khalfaoui, R., Solarin, S.A. and M. Shahbaz. 2018. Analyzing the timefrequency lead-lag relationship between oil and agricultural commodities. Energy Economics 76: 470-494.

World Bank. 2019. Commodity Market Outlook, October.

Yahya, M., Oglend, A. and R.E. Dahl. 2019. Temporal and spectral dependence between crude oil and agricultural commodities: A wavelet-based copula approach. Energy Economics 80: 277-296.

Zhang, C. and X. Qu. 2015. The effect of global oil price shocks on China's agricultural commodities. Energy Economics 51: 354-364.

Zimmer, D.M. 2012. The role of copulas in the housing crisis. The Review of Economics and Statistics 94: 607-620. 


\section{Appendixes}

\section{Appendix A}
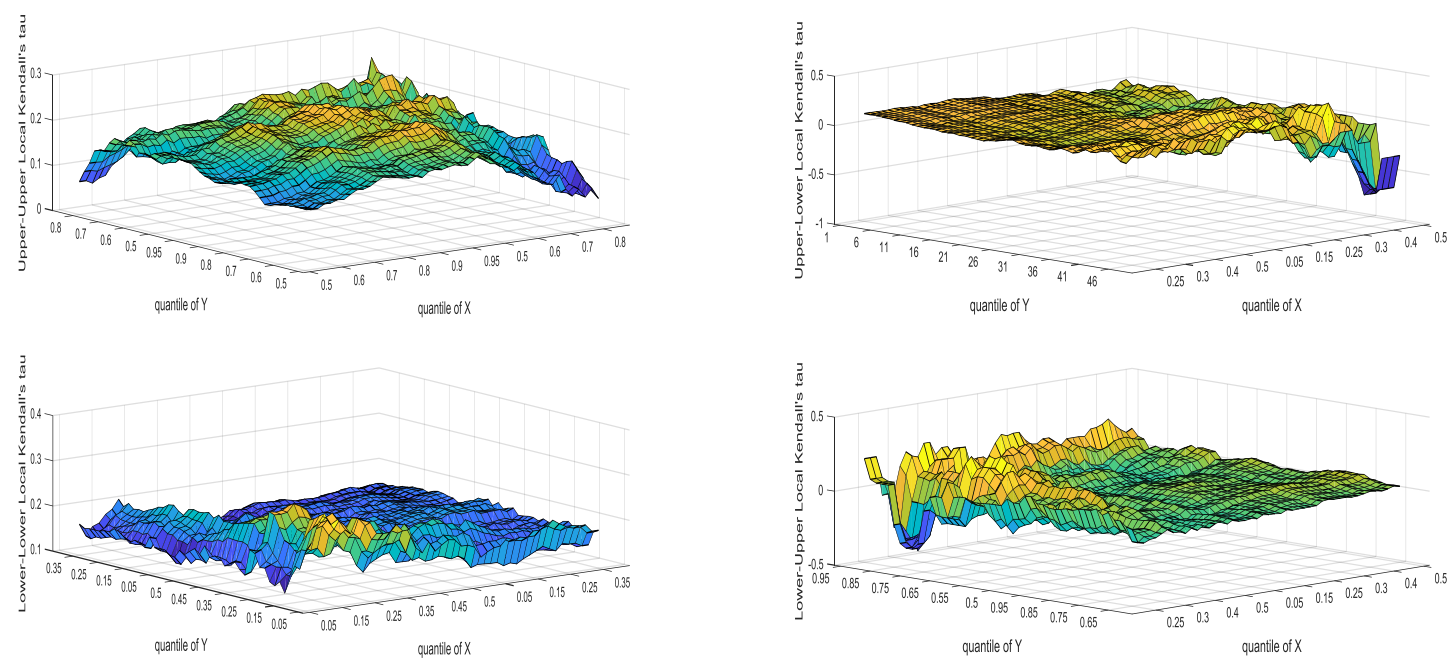

(a) Lower-lower and upper-upper

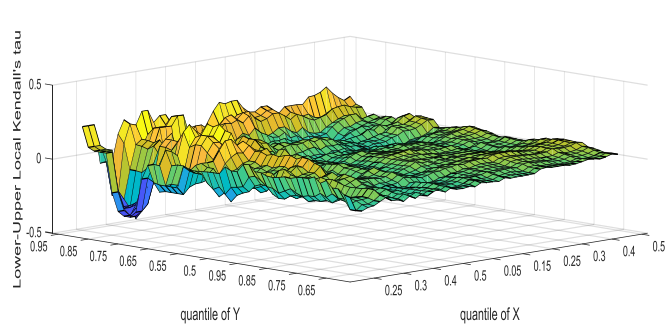

(b) Upper-lower and lower-Upper

Figure A1. Local dependence surfaces in different quadrants based on Kendall's tau of product copula (RICIA-RICIM)

(Note: The blue surfaces and yellow surfaces are the theoretical and empirical local dependence surfaces.)
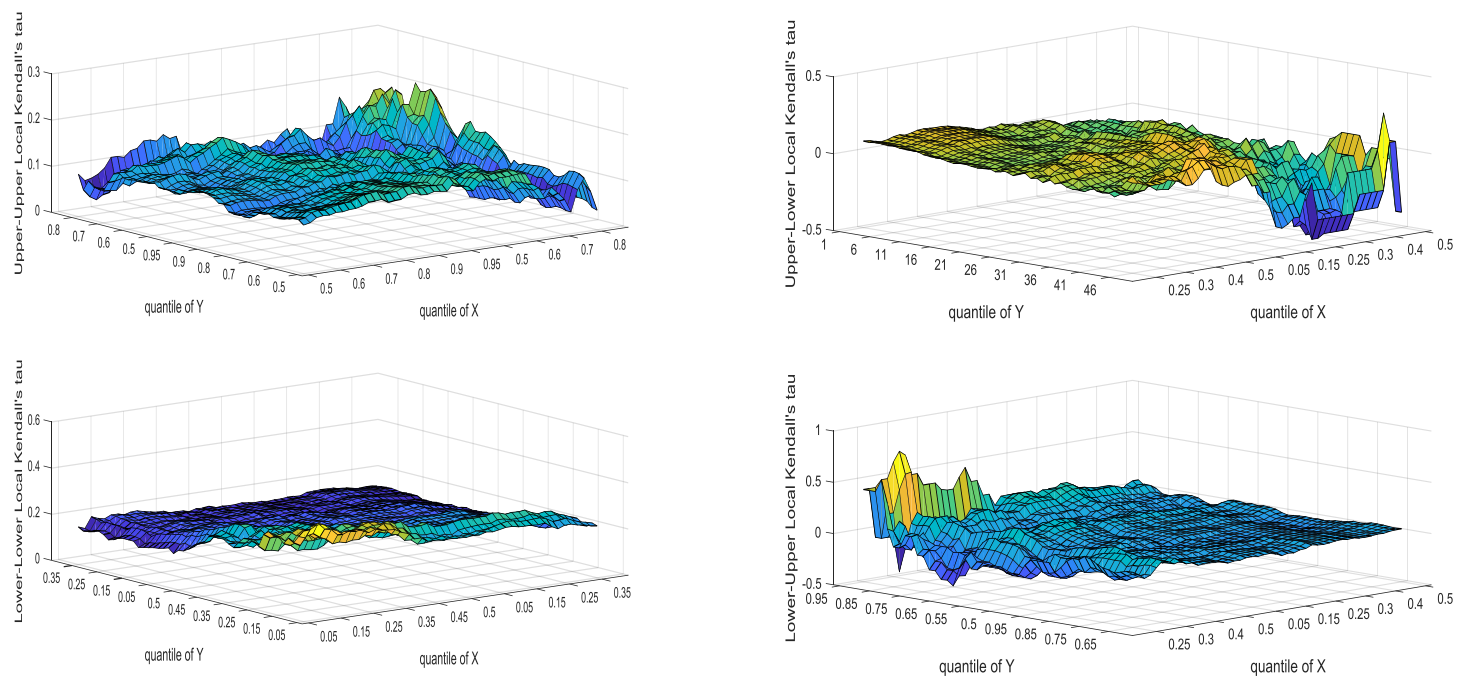

(a) Lower-lower and upper-upper

(b) Upper-lower and lower-Upper

Figure A2. Local dependence surfaces in different quadrants based on Kendall's tau of product copula (RICIA-RICIE)

(Note: The blue surfaces and yellow surfaces are the theoretical and empirical local dependence surfaces.) 

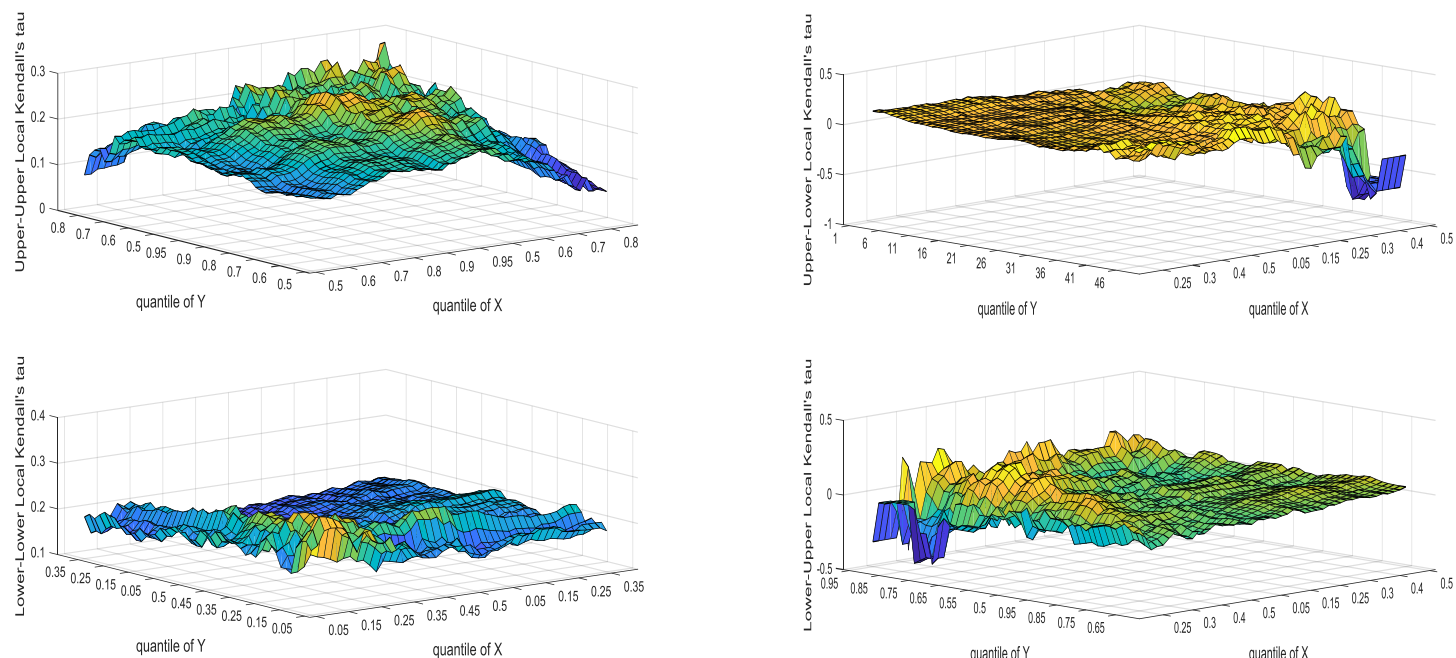

(a) Lower-lower and upper-upper

(b) Upper-lower and lower-Upper

Figure A3. Local dependence surfaces in different quadrants based on Kendall's tau of product copula (RICIM-RICIE)

(Note: The blue surfaces and yellow surfaces are the theoretical and empirical local dependence surfaces.) 


\section{Figures}

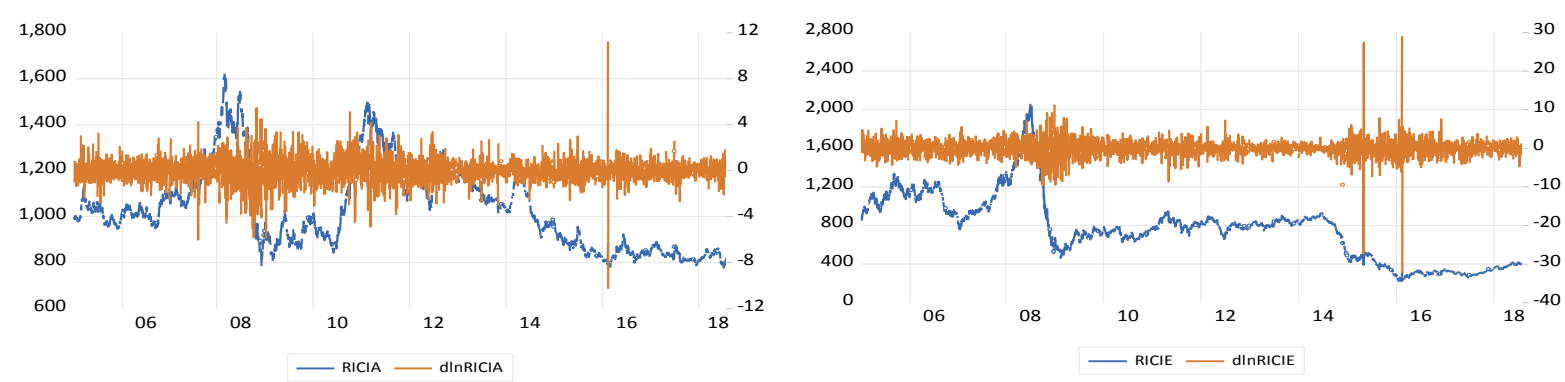

$\begin{array}{ll}\text { (a) RICIA } & \text { (b) RICIE }\end{array}$

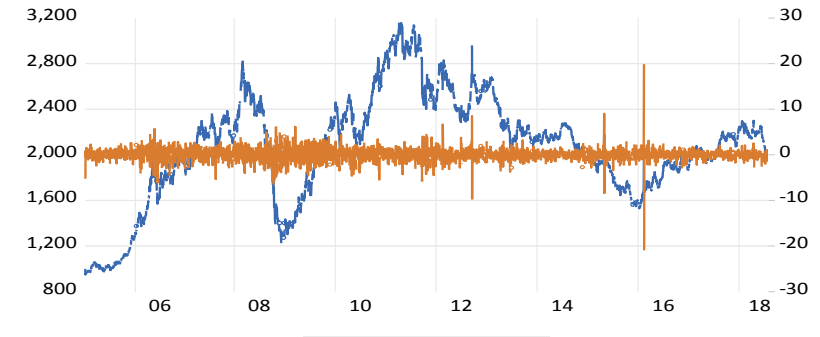

(c) RICIM

Figure 1. Commodity price indexes dynamics (log returns and standardised residuals) 


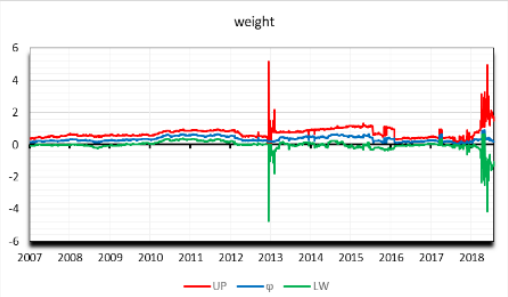

weight

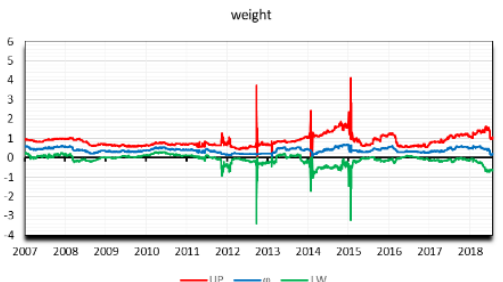

weight

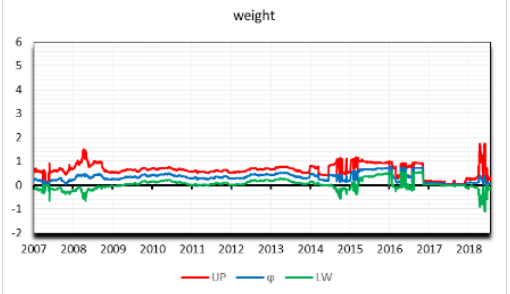

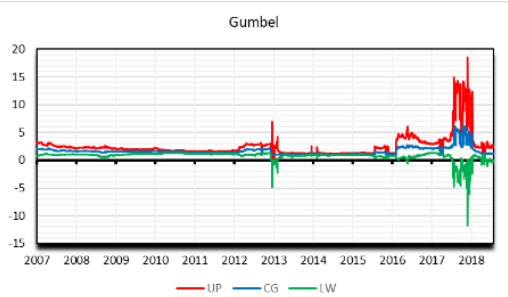

(a) RICIA-RICIM

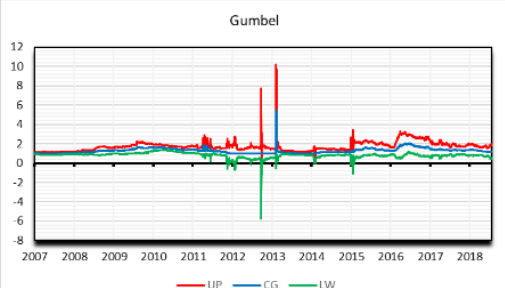

(b) RICIA-RICIE

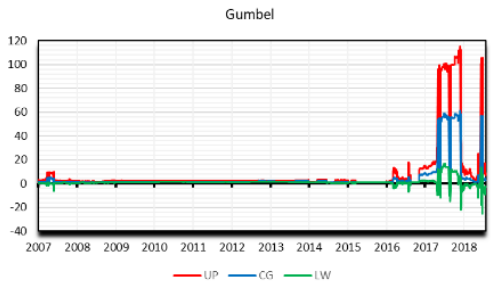

(c) RICIM-RICIE

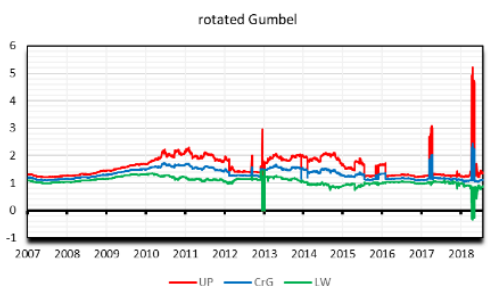

rotated Gumbel

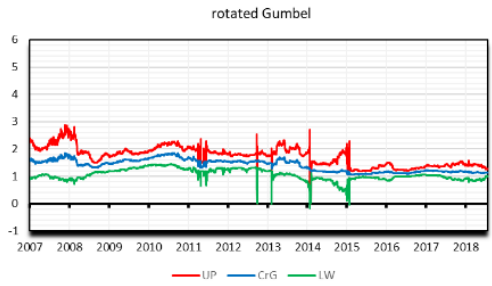

rotated Gumbel

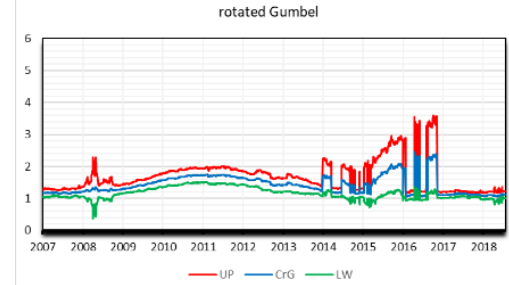

Figure 2. Rolling window analysis for the best mixture copula

(Notes: (i) UP (red line) and LW (green line) represent 5\% confidence interval limits; (ii) if the blue line lies in the confidence interval, then the parameter is significant.) 


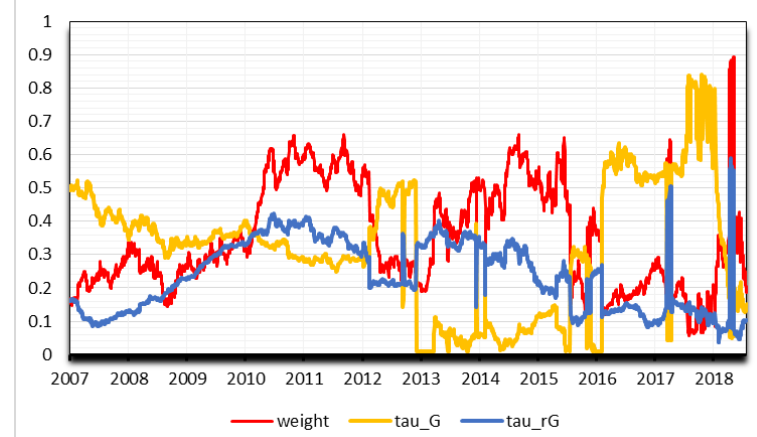

(a) RICIA-RICIM

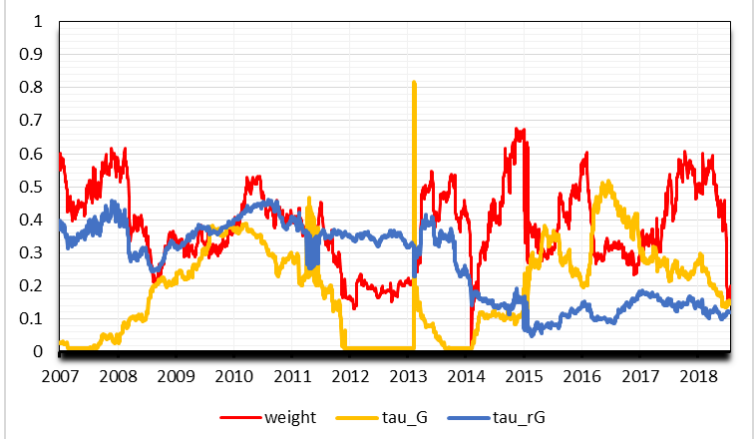

(b) RICIA-RICIE

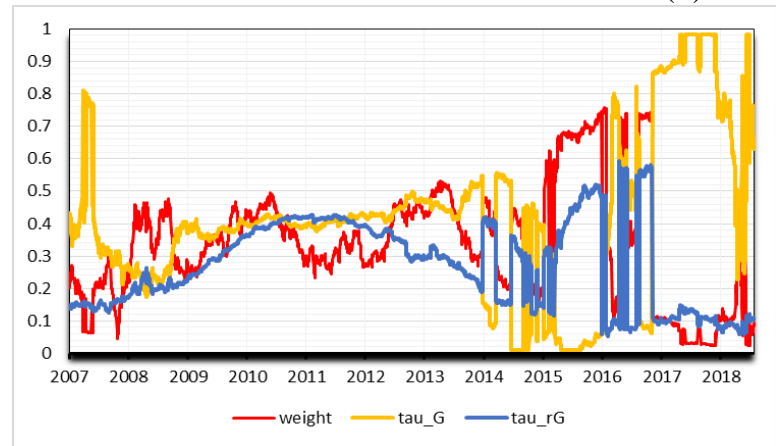

(c) RICIM-RICIE

Figure 3. Rolling window analysis for the best mixture copula using tau transformation 


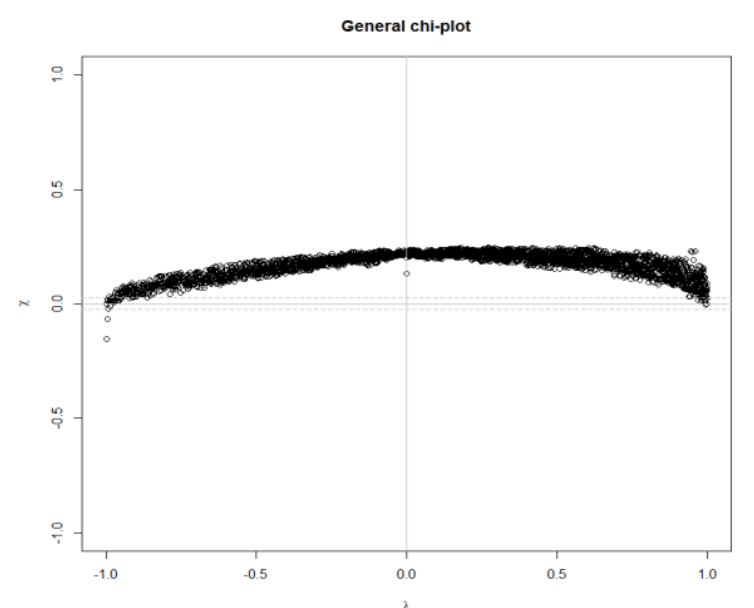

(a) RICIA-RICIM

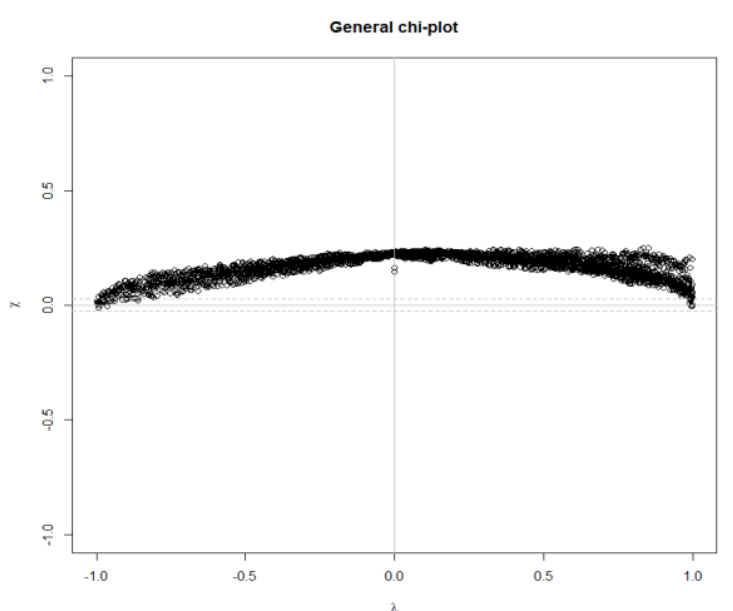

(b) RICIA-RICIE

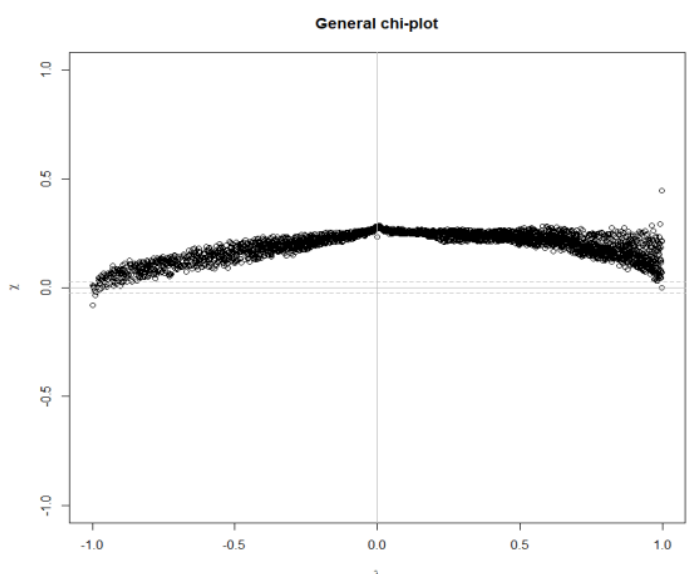

(c) RICIM-RICIE

Figure 4. Chi-plots illustrated by each pair of commodity indexes 


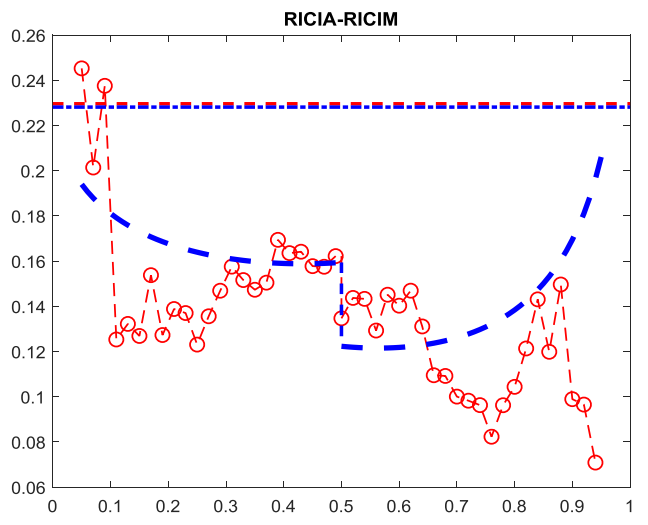

(a) RICIA-RICIM

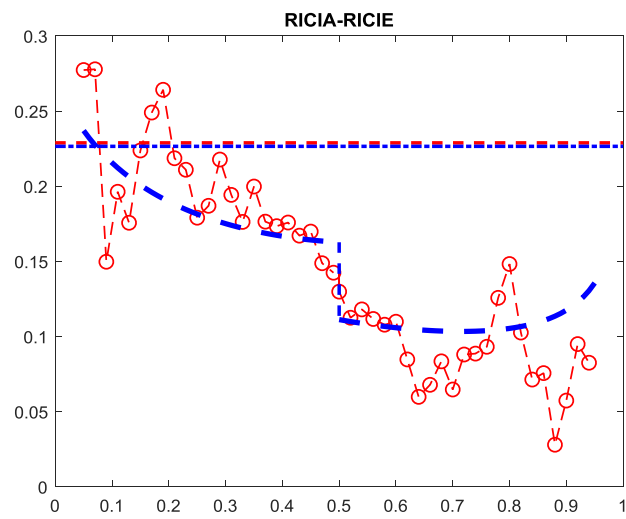

(b) RICIA-RICIE

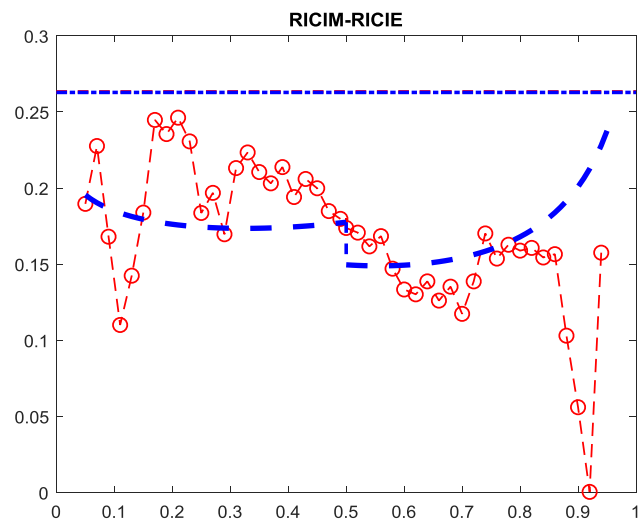

(c) RICIM-RICIE

Figure 5. Lower-lower and upper-upper quantiles global and local Kendall's tau plots along the main diagonal

(Note: The red and blue dotted lines represent the empirical and theoretical global Kendall's tau (there are no significant differences between the empirical and the theoretical global Kendall's tau). The blue smooth and the red non-smooth lines with circles represent the theoretical and the empirical local Kendall's tau along the main diagonal.) 


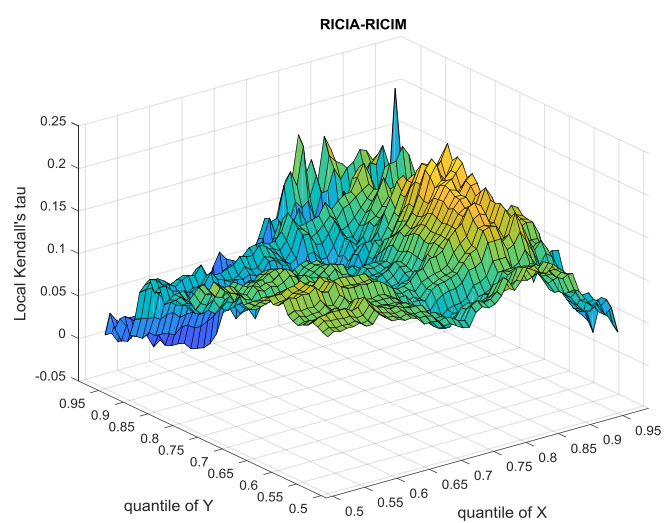

(a) RICIA-RICIM upper tails

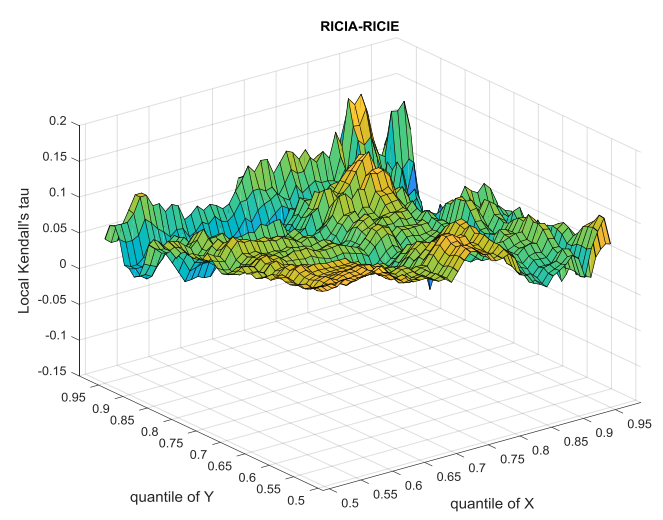

c) RICIA-RICIE upper tails

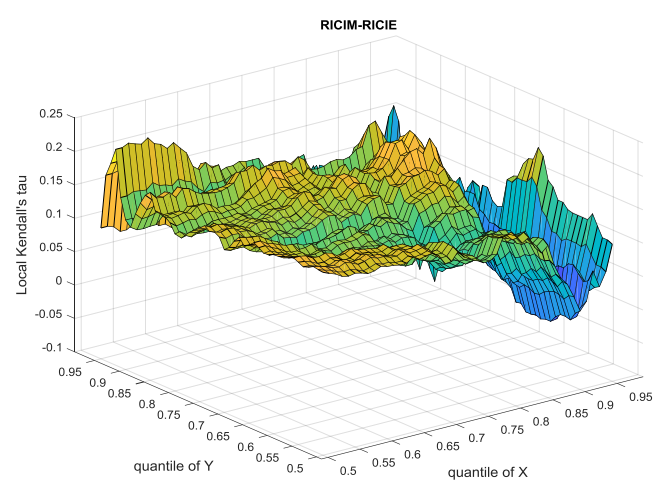

(e) RICIM-RICIE upper tails

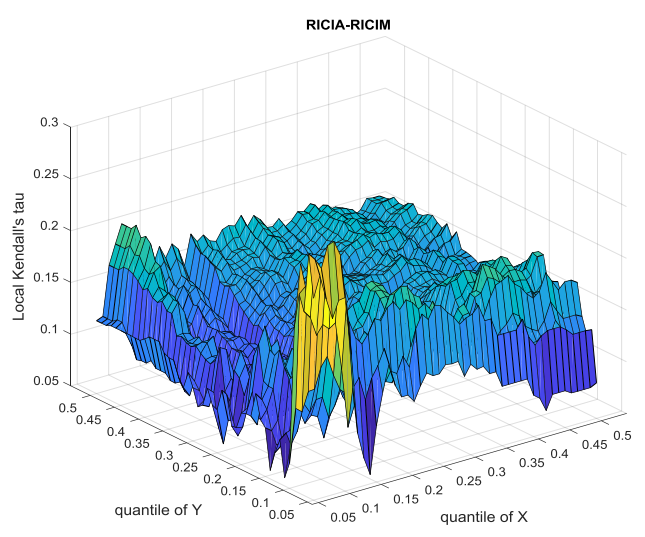

(b) RICIA-RICIM lower tails

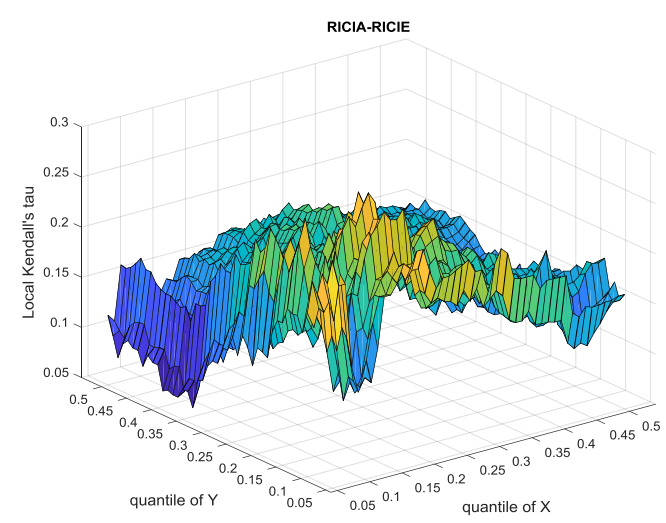

(d) RICIA-RICIE lower tails

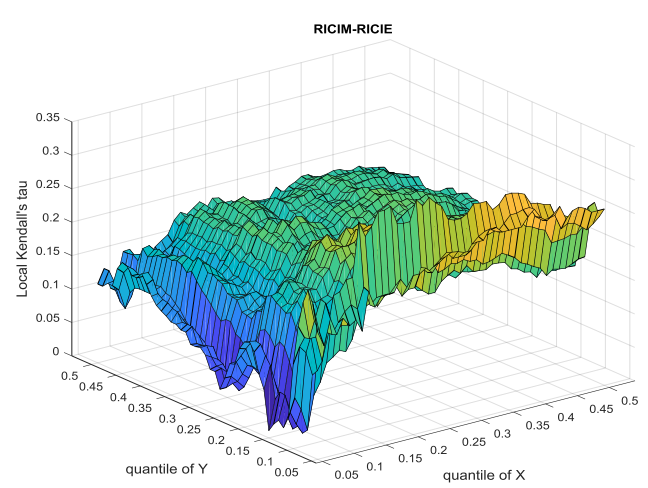

(f) RICIM-RICIE lower tails

Figure 6. Local Kendall's tau plots for upper and lower tails in quantiles

(Note: The blue surfaces and yellow surfaces are the theoretical and empirical local dependence surfaces.) 


\section{Tables}

Table 1. Summary statistics

\begin{tabular}{llll}
\hline & dlnRICIA & dlnRICIE & dlnRICIM \\
\hline Mean & 0.002 & 0.009 & 0.143 \\
Median & -0.020 & 0.048 & 0.040 \\
Maximum & 11.23 & 29.00 & 19.88 \\
Minimum & -10.28 & -32.31 & -20.94 \\
Std. Dev. & 1.056 & 2.191 & 1.410 \\
Skewness & -0.131 & -0.342 & -0.349 \\
Kurtosis & 12.14 & 40.72 & 31.52 \\
Jarque-Bera & $11901.4 * * *$ & $202564.0 * * *$ & $115840.1 * * *$ \\
\hline Stationary analysis & & & $-65.19 * * *$ \\
ADF & $-58.85 * * *$ & $-67.44 * * *$ & $-65.16^{* * * *}$ \\
PP & $-58.86^{* * *}$ & $-67.45^{* * *}$ & 0.336 \\
KPSS & 0.093 & 0.109 & 3414 \\
\hline Observations & 3414 & 3414 &
\end{tabular}


Table 2. ARMA (1, 0)-GARCH $(2,1)$ marginal model

\begin{tabular}{|c|c|c|c|c|c|c|c|c|c|}
\hline & \multicolumn{3}{|c|}{ RICIA } & \multicolumn{3}{|c|}{ RICIM } & \multicolumn{3}{|c|}{ RICIE } \\
\hline & Coeff. & Std.E & $\mathrm{t}$-value & Coeff. & Std.E & $\mathrm{t}$-value & Coeff. & Std.E & $\mathrm{t}$-value \\
\hline$\overline{\text { Cst (M) }}$ & -0.014 & 0.014 & -1.007 & $0.034 * *$ & 0.016 & 2.079 & 0.034 & 0.023 & 1.441 \\
\hline $\mathrm{AR}(1)$ & 0.017 & 0.017 & 1.052 & $-0.051 * * *$ & 0.017 & -3.001 & $-0.045^{* *}$ & 0.017 & -2.546 \\
\hline Cst (V) & $0.006 * *$ & 0.003 & 2.201 & $0.020 * *$ & 0.008 & 2.325 & $0.018 *$ & 0.010 & 1.690 \\
\hline $\operatorname{ARCH}(\alpha 1)$ & $0.070 * * *$ & 0.023 & 3.065 & $0.081 * * *$ & 0.024 & 3.298 & $0.110 * * *$ & 0.026 & 4.144 \\
\hline $\mathrm{ARCH}(\alpha 2)$ & -0.026 & 0.026 & -1.008 & -0.011 & 0.028 & -0.417 & $-0.052 *$ & 0.028 & -1.815 \\
\hline GARCH $(\beta 1)$ & $0.949 * * *$ & 0.014 & 67.79 & $0.920 * * *$ & 0.020 & 44.73 & $0.939 * * *$ & 0.016 & 56.94 \\
\hline Student (DF) & $6.749 * * *$ & 0.955 & 7.066 & $5.924 * * *$ & 0.719 & 8.236 & $6.782 * * *$ & 0.914 & 7.419 \\
\hline Log Likelihood & & -4553.7 & & & -5375.0 & & & -6712.4 & \\
\hline Akaike & & 2.671 & & & 3.152 & & & 3.936 & \\
\hline Q (10) & & 5.173 & & & 11.03 & & & 7.686 & \\
\hline $\mathrm{p}$-value & & [0.818] & & & {$[0.273]$} & & & {$[0.566]$} & \\
\hline $\mathrm{Q}^{2}(10)$ & & 3.263 & & & 5.936 & & & 6.924 & \\
\hline p-value & & [0.859] & & & {$[0.547]$} & & & {$[0.436]$} & \\
\hline $\mathrm{ARCH}$ & & 1.384 & & & 2.488 & & & 2.179 & \\
\hline p-value & & {$[0.250]$} & & & [0.083] & & & {$[0.113]$} & \\
\hline
\end{tabular}

Notes: (i) ***, ** and $*$ denote significance at the $1 \%, 5 \%$ and $10 \%$ levels, respectively; (ii) Q (10) is the Ljung-Box statistic for serial correlation in the model residuals computed with 10 lags. 
Table 3. Individual copula results

\begin{tabular}{|c|c|c|c|c|c|c|c|c|c|}
\hline & & $\begin{array}{l}\text { RICIA- } \\
\text { RICIM }\end{array}$ & $\begin{array}{l}\text { RICIA- } \\
\text { RICIE }\end{array}$ & $\begin{array}{c}\text { RICIM- } \\
\text { RICIE }\end{array}$ & & & $\begin{array}{l}\text { RICIA- } \\
\text { RICIM }\end{array}$ & $\begin{array}{l}\text { RICIA- } \\
\text { RICIE }\end{array}$ & $\begin{array}{c}\text { RICIM- } \\
\text { RICIE }\end{array}$ \\
\hline \multirow{5}{*}{ Gumbel } & $C_{g}$ & 1.262 & 1.256 & 1.324 & \multirow{5}{*}{$\begin{array}{l}\text { Rotated } \\
\text { Gumbel }\end{array}$} & $C_{r g}$ & 1.276 & 1.275 & 1.335 \\
\hline & s.e. & 0.016 & 0.016 & 0.017 & & s.e. & 0.016 & 0.016 & 0.017 \\
\hline & LR & 198.6 & 192.5 & 280.0 & & LR & 230.4 & 231.1 & 307.8 \\
\hline & AIC & -395.3 & -383.1 & -558.1 & & AIC & -458.8 & -460.3 & -613.6 \\
\hline & $\mathrm{BIC}$ & -389.2 & -377.0 & -552.0 & & $\mathrm{BIC}$ & -452.7 & -454.2 & -607.4 \\
\hline \multirow{5}{*}{ Clayton } & $C_{C L}$ & 0.463 & 0.463 & 0.548 & \multirow{5}{*}{$\begin{array}{l}\text { Rotated } \\
\text { Clayton }\end{array}$} & $C_{r C L}$ & 0.404 & 0.399 & 0.502 \\
\hline & s.e. & 0.026 & 0.026 & 0.027 & & s.e. & 0.026 & 0.025 & 0.027 \\
\hline & LR & 203.2 & 200.6 & 263.5 & & LR & 154.2 & 155.1 & 220.7 \\
\hline & AIC & -404.5 & -399.3 & -525.0 & & AIC & -306.4 & -308.3 & -439.4 \\
\hline & $\mathrm{BIC}$ & -398.4 & -393.1 & -518.9 & & $\mathrm{BIC}$ & -300.3 & -302.2 & -433.3 \\
\hline
\end{tabular}

Notes: (i) $* * *$ denotes significance at the $1 \%$ level; (ii) bold values indicate the best copula model among all the analysed individual copula models; (iii) s.e. means standard errors; (iv) 3,413 observations. 
Table 4. Mixture copula results

\begin{tabular}{|c|c|c|c|c|c|c|c|c|c|}
\hline & & $\begin{array}{l}\text { RICIA- } \\
\text { RICIM }\end{array}$ & $\begin{array}{l}\text { RICIA- } \\
\text { RICIE }\end{array}$ & $\begin{array}{l}\text { RICIM- } \\
\text { RICIE }\end{array}$ & & & $\begin{array}{l}\text { RICIA- } \\
\text { RICIM }\end{array}$ & $\begin{array}{l}\text { RICIA- } \\
\text { RICIE }\end{array}$ & $\begin{array}{l}\text { RICIM- } \\
\text { RICIE }\end{array}$ \\
\hline$C_{m i x 1}$ & & & & & $C_{m i x 2}$ & & & & \\
\hline \multirow{2}{*}{ weight } & $\varphi$ & 0.386 & 0.580 & 0.425 & weight & $\varphi$ & 0.820 & 0.732 & 0.779 \\
\hline & s.e. & 0.094 & 0.064 & 0.069 & & s.e. & 0.052 & 0.140 & 0.047 \\
\hline \multirow[t]{2}{*}{ Gumbel } & $C_{G}$ & 1.454 & 1.208 & 1.575 & $\begin{array}{l}\text { Rotated } \\
\text { Gumbel }\end{array}$ & $C_{r G}$ & 1.247 & 1.303 & 1.298 \\
\hline & s.e. & 0.171 & 0.031 & 0.143 & & s.e. & 0.022 & 0.081 & 0.025 \\
\hline \multirow{5}{*}{ Clayton } & $C_{C L}$ & 0.424 & 0.854 & 0.462 & Rotated & $C_{r C L}$ & 1.143 & 0.532 & 1.221 \\
\hline & s.e. & 0.099 & 0.150 & 0.083 & Clayton & s.e. & 0.357 & 0.378 & 0.272 \\
\hline & LR & 242.6 & 242.3 & 326.3 & & LR & 244.1 & 243.9 & 330.4 \\
\hline & AIC & -479.3 & -478.7 & -646.6 & & AIC & -482.2 & -481.8 & -654.8 \\
\hline & BIC & -460.9 & -460.3 & -628.2 & & BIC & -463.8 & -463.4 & -636.4 \\
\hline \multirow{3}{*}{$\begin{array}{c}\mathrm{C}_{\text {mix } 3} \\
\text { weight }\end{array}$} & & & & & $C_{m i x 4}$ & & & & \\
\hline & $\varphi$ & 0.248 & 0.403 & 0.291 & weight & $\varphi$ & 0.677 & 0.505 & 0.638 \\
\hline & s.e. & 0.064 & 0.101 & 0.058 & & s.e. & 0.058 & 0.067 & 0.051 \\
\hline \multirow[t]{2}{*}{ Gumbel } & $C_{G}$ & 1.607 & 1.189 & 1.726 & Clayton & $C_{C L}$ & 0.485 & 0.768 & 0.572 \\
\hline & s.e. & 0.178 & 0.068 & 0.161 & \multirow{6}{*}{$\begin{array}{l}\text { Rotated } \\
\text { Clayton }\end{array}$} & s.e. & 0.056 & 0.126 & 0.060 \\
\hline \multirow{5}{*}{$\begin{array}{l}\text { Rotated } \\
\text { Gumbel }\end{array}$} & $C_{r G}$ & 1.220 & 1.375 & 1.251 & & $C_{r C L}$ & 0.808 & 0.408 & 0.939 \\
\hline & s.e. & 0.027 & 0.088 & 0.029 & & s.e. & 0.180 & 0.073 & 0.165 \\
\hline & LR & 245.5 & 244.1 & 332.3 & & LR & 241.1 & 242.0 & 323.7 \\
\hline & AIC & -485.1 & -482.3 & -658.7 & & AIC & -476.3 & -478.0 & -641.4 \\
\hline & BIC & -466.7 & -463.9 & -640.3 & & $\mathrm{BIC}$ & -457.9 & -459.6 & -623.0 \\
\hline
\end{tabular}

Notes: (i) *** denotes significance at the $1 \%$ level; (ii) bold values indicate the best copula model among all the analysed mixture copula models; (iii) s.e. means standard errors; (iv) 3,413 observations. 
Table 5. DCC model conditional correlations summary statistics

\begin{tabular}{lcccr}
\hline & Mean & St Dev & Min & Max \\
\hline RICIA/RICIM & 0.414 & 0.128 & 0.094 & 0.740 \\
RICIA/RICIE & 0.414 & 0.127 & 0.180 & 0.772 \\
RICIM/RICIA & 0.469 & 0.133 & 0.130 & 0.732 \\
\hline
\end{tabular}

Note: Summary statistics for time-varying conditional correlations $\rho$. 
Table 6. Hedge ratio (long/short) summary statistics

\begin{tabular}{lcccc}
\hline & Mean & St Dev & Min & Max \\
\hline RICIA/RICIM & 0.420 & 4.540 & 0.030 & 224.2 \\
RICIA/RICIE & 0.260 & 0.070 & 0.110 & 0.550 \\
RICIM/RICIA & 0.540 & 0.190 & 0.000 & 1.280 \\
RICIM/RICIE & 0.390 & 0.130 & 0.000 & 0.980 \\
RICIE/RICIA & 0.670 & 0.260 & 0.150 & 1.500 \\
RICIE/RICIM & 0.640 & 2.550 & 0.140 & 126.3 \\
\hline Note: Summary statistics for hedge ratios $\beta$. & &
\end{tabular}

Note: Summary statistics for hedge ratios $\beta$. 
Table 7. Portfolio weights summary statistics

\begin{tabular}{lcccr}
\hline & Mean & St Dev & Min & Max \\
\hline RICIA/RICIM & 0.710 & 0.140 & 0.000 & 1.000 \\
RICIA/RICIE & 0.840 & 0.120 & 0.180 & 1.000 \\
RICIM/RICIE & 0.690 & 0.170 & 0.010 & 1.000 \\
\hline \multicolumn{2}{l}{ Note: Summary statistics for portfolio weights $\mathrm{w}}$.
\end{tabular}

Note: Summary statistics for portfolio weights $w$. 